\title{
Prognostic value of tumor-infiltrating lymphocytes in esophageal cancer: an updated meta-analysis of 30 studies with 5,122 patients
}

\author{
Yibo Gao ${ }^{1 \#}$, Wei Guo ${ }^{1 \#}$, Xiao Geng ${ }^{1 \#}$, Yidong Zhang ${ }^{1,2 \#}$, Guochao Zhang ${ }^{1}$, Bin Qiu ${ }^{1}$, Fengwei Tan ${ }^{1}$, \\ Qi Xue ${ }^{1}$, Shugeng Gao ${ }^{1}$, Jie $\mathrm{He}^{1}$ \\ ${ }^{1}$ Department of Thoracic Surgery, National Cancer Center/National Clinical Research Center for Cancer/Cancer Hospital, Chinese Academy of \\ Medical Sciences and Peking Union Medical College, Beijing, China; ${ }^{2}$ Big Data Institute, Li Ka Shing Center for Health Information and Discovery, \\ University of Oxford, Oxford, United Kingdom \\ Contributions: (I) Conception and design: J He, Y Gao, W Guo; (II) Administrative support: J He, S Gao, Q Xue, F Tan, Y Gao;(III) Provision of \\ study materials or patients: W Guo, X Geng, Y Zhang; (IV) Collection and assembly of data: W Guo, X Geng, Y Zhang; (V) Data analysis and \\ interpretation: X Geng, Y Zhang, W Guo, G Zhang, B Qiu, F Tan, Y Gao; (VI) Manuscript writing: All authors; (VII) Final approval of manuscript: \\ All authors. \\ "These authors contributed equally to this work. \\ Correspondence to: Dr. Jie He; Dr. Shugeng Gao; Dr. Yibo Gao. Department of Thoracic Surgery, National Cancer Center/National Clinical \\ Research Center for Cancer/Cancer Hospital, Chinese Academy of Medical Sciences and Peking Union Medical College, Beijing, China. \\ Email: prof.jiehe@gmail.com; gaoshugeng@vip.sina.com; gaoyibo@cicams.ac.cn.
}

\begin{abstract}
Background: The prognostic role of tumor-infiltrating lymphocytes (TILs) in esophageal cancer (EC) patients is controversial; therefore, we performed a meta-analysis to obtain a consensus.

Methods: The PubMed, PubMed Central, Embase, Cochrane Library, and Web of Science databases were searched. The pooled hazard ratios (HRs) with $95 \%$ confidence intervals (CIs) were calculated using fixed effect or random effect models depending on the heterogeneity.

Results: A total of 30 articles comprising 5,122 patients were included in this meta-analysis. High levels of generalized TIL infiltration were associated with better overall survival (OS) (HR =0.67, 95\% CI: 0.47-0.95, $\mathrm{P}=0.02)$ in EC patients. High CD8+ T-cell infiltration and high CD4+ T-cell infiltration were associated with better $\mathrm{OS}(\mathrm{HR}=0.68,95 \% \mathrm{CI}: 0.60-0.78, \mathrm{P}<0.001$; HR =0.70, 95\% CI: 0.57-0.85, $\mathrm{P}<0.001$, respectively). However, the pooled results showed that neither $\mathrm{CD} 3+$ nor FOXP3 + T-cell infiltration were associated with patient survival $(\mathrm{P}>0.05)$. Moreover, for esophageal squamous cell carcinoma (ESCC), high CD8+ T lymphocyte infiltration in the TN (Tumor nest) or TS (Tumor stroma) significantly predicted better OS (pooled HR =0.70, 95\% CI: 0.57-0.85; P=0.001; pooled HR =0.77, 95\% CI: 0.65-0.91; P=0.003).

Conclusions: High levels of generalized TILs, high CD8+ T-cell infiltration and high CD4+ T-cell infiltration have the potential to serve as prognostic markers in EC patients. Moreover, high CD8+ TIL in TNs or TS can predict better OS in ESCC patients.
\end{abstract}

Keywords: Tumor-infiltrating lymphocytes; esophageal cancer; prognosis; tumor immunity; meta-analysis

Submitted Jan 01, 2020. Accepted for publication Jun 04, 2020.

doi: $10.21037 /$ atm-20-151

View this article at: http://dx.doi.org/10.21037/atm-20-151

\section{Introduction}

Esophageal cancer (EC) is the eighth most common cancer and the sixth most common cause of cancerrelated death worldwide, and its incidence continues to increase (1). EC mainly has two different pathological types: esophageal squamous cell carcinoma (ESCC) and esophageal adenocarcinoma (EAC) (2). ESCC accounts for approximately $90 \%$ of ECs worldwide and is the predominant subtype of EC in Asia, Africa, and South America, while EAC remains the predominant subtype 
in North America and Europe (2). ESCC arises from epithelial cells, whereas EAC arises from metaplastic Barrett's esophagus (3). These two subtypes differ with regard to etiology, ethnic distribution, pathogenesis, precursor lesions, and location in the esophagus (4). Despite significant advances in screening, diagnosis and treatment modalities, the long-term outcomes of EC patients remain poor. At present, the prognosis of patients is mainly predicted by the histopathology-based TNM classification system, which does not provide sufficiently detailed information to delineate definitive clinical outcomes in EC patients. Therefore, a new biological marker that can more precisely stratify patients with regard to long-term prognosis is needed.

Emerging evidence suggests that tumor-infiltrating lymphocytes (TILs) can be a potential prognostic biomarker. The correlation between TILs and prognosis has been studied in several types of solid tumors, such as lung cancer (5), breast cancer (6), colorectal cancer (7), melanoma (8), hepatocellular carcinoma (9) and ovarian cancer (10). The heterogeneous population of TILs mainly includes $\mathrm{T}$ cells as well as smaller populations of $\mathrm{B}$ cells and natural killer cells $(11,12)$. After decades of research, scientists have reached a consensus that TILs play a bidirectional role in the tumor microenvironment (13). On the one hand, TILs can suppress tumor growth by directly destroying tumor cells; on the other hand, TILs can select tumor cells that are suitable for growth in immunocompetent hosts (12). The distribution of TILs can also influence the prognosis to some extent. TILs divide into two groups based on their locations: (I) tumor nest (TN), which contains cells infiltrating within the epithelium of the invasive tumor cell nests; and (II) tumor stroma (TS), which contains cells infiltrating either the tumor stroma adjacent to the cancer epithelia or the stroma along the invasive margin of the cancer epithelia. Overall, although the influence of TILs on tumor progression is highly complex, their pivotal localization in the tumor microenvironment and their influence on a patient's clinical outcome cannot be denied.

Before 2000, researchers had been studying the association between TILs and the prognosis of EC patients, and efforts in this direction have not ceased, with continued improvements in techniques and more in-depth insights relating to the field of tumor immunology. Many studies have verified TILs for use in prognostic prediction in addition to their crucial role in tumor-associated immune responses in EC (14-19). However, the prognostic role of TILs in EC remains controversial, varying with the distribution site and cell types. Zhang et al. found that high infiltration of CD8+ T cells in TS was associated with better clinical outcome for ESCC patients (19); however, the infiltration of CD8+ lymphocytes showed no prognostic value in Chen KY's study (16). Svensson et al. found that high infiltration of CD8 $+\mathrm{T}$ cells was associated with better clinical outcome for EAC patients (20), whereas no correlation between the infiltration of CD8+ T cells and clinical outcome was found in either Rauser's study or Stein's study $(15,21)$. Chen et al. revealed that patients with a high density of CD4+ $\mathrm{T}$ cells had a better outcome (16), whereas no correlation between the infiltration of CD4+ T cells and clinical outcome was reported in Zhu's study (17). Zhang et al. stated that high infiltration of FOX3 + T cells was associated with worse outcomes (18), but Stein et al. revealed contrasting results (15). Thus, a meta-analysis that can systematically and comprehensively gather and analyze all available data is urgently needed. The present work aimed to evaluate the prognostic role of TILs in EC.

We present the following article in accordance with the PRISMA 2009 reporting checklist (available at http:// dx.doi.org/10.21037/atm-20-151).

\section{Methods}

\section{Search strategy}

This meta-analysis was performed according to the Preferred Reporting Items for Systematic Reviews and Meta-Analyses (PRISMA) guidelines and the Meta-analysis of Observational Studies in Epidemiology (MOOSE) guidelines $(22,23)$.

The PubMed, Embase, Cochrane Library, and Web of Science databases (last update on March 20, 2020) were searched for relevant articles. The following keywords and combinations were used in the search strategy: "(((((Prognosis) OR Prognostic) OR Survival) OR Outcome $))$ AND OR Esophageal Neoplasm) OR Neoplasm, Esophageal) OR Esophagus Neoplasm) OR Esophagus Neoplasms) OR Neoplasm, Esophagus) OR Neoplasms, Esophagus) OR Neoplasms, Esophageal) OR Cancer of Esophagus) OR Cancer of the Esophagus) OR Esophagus Cancer) OR Cancer, Esophagus) OR Cancers, Esophagus)) AND ((((()((()((TILS) OR Lymphocytes, Tumor-Infiltrating) OR Lymphocytes, Tumor Infiltrating) OR Tumor-Infiltrating Lymphocytes) OR Lymphocyte, Tumor-Infiltrating) OR Tumor Infiltrating Lymphocytes) OR Tumor-Infiltrating 
Lymphocyte) OR Tumor-Derived Activated Cells) OR Activated Cell, Tumor-Derived) OR Activated Cells, Tumor-Derived) OR Tumor Derived Activated Cells) OR Tumor-Derived Activated Cell))." In addition to the title, abstract, and full text, the reference lists of identified articles were perused in order to ascertain other potential studies. Eligible reports were identified by 2 reviewers (Yidong Zhang and Xiao Geng), and disagreements were resolved by a third reviewer (Wei Guo).

\section{Inclusion and exclusion criteria}

Articles extracted from the databases were selected in accordance with the following criteria: (I) data pertaining to the prognostic role of either TILs or specific TIL subsets in EC were reported; (II) HRs and 95\% CIs could be extracted directly or indirectly; and (III) sample size was greater than 50. The exclusion criteria were as follows: (I) small sample size $(<50)$ that might cause publication bias; or (II) certain types of studies, including encompassing reviews, letters, case reports, animal trials, and conference abstracts. Additionally, if a particular patient cohort was included in more than 1 study, only the most recent or complete study was considered.

\section{Data extraction}

Two researchers independently collected data, including author information, publication year, tumor histology, TIL subsets and distribution sites, population origin, tumor stage, cutoff values, sample size, follow-up period, detection methods, HRs, and 95\% CIs. Overall survival (OS), disease-free survival (DFS), and cancer-specific survival (CSS) (where possible) were selected as indexes in our study because these data were available in most of the included studies. If multivariate anallysis was performed, it was preferred over univariate analysis because it offers some control over other potential confounding factors. KaplanMeier curves were used to extract HR with $95 \%$ CI if it could not be obtained directly from the article.

The quality of each included study was evaluated independently by 2 researchers according to the NewcastleOttawa Quality Assessment Scale (NOS) (24). Scores ranged from 0 to 9 for quality assessment, and studies with scores $\geq 6$ were considered to be of high quality.

\section{Statistical analysis}

The prognostic roles of different TIL subsets at different sites within the tumor microenvironment in EC patients were assessed by HRs and $95 \%$ CIs. An HR $>1$ was considered to indicate a worse prognosis among patients with high TIL infiltration, whereas an $\mathrm{HR}<1$ was considered to indicate a better prognosis. If HRs and $95 \%$ CIs were reported, they were retrieved directly. Otherwise, the HR was calculated with data extracted from KaplanMeier survival curves using Engauge Digitizer version 4.1 (M. Mitchell, Engauge Digitizer, http://digitizer. sourceforge.net) (25). Important supplementary information was obtained by sending emails to the corresponding authors. The $\mathrm{I}^{2}$ statistic and chi-square test ( $\mathrm{P}$ value) were performed, and forest plots were visually inspected to assess statistical heterogeneity $(26,27)$. When $\mathrm{I}^{2}$ was below $50 \%$ and/or the $\mathrm{P}$-value was greater than 0.05 , heterogeneity was suggested, and a random effects model (the DerSimonianLaird method) was used; otherwise, a fixed effects model was used. Subgroup analysis was performed to further analyze integrated data derived from a sufficient number of studies, which showed clinical significance. Publication bias was assessed using Egger's linear regression test and Begg's funnel plot, and $\mathrm{P}<0.05$ was thought to have statistical significance. All analyses were performed using STATA (Stata Corporation, College Station, TX, USA), and significance was defined as a $\mathrm{P}$ value $<0.05$.

\section{Results}

\section{Study characteristics}

Using the search strategy described above, 13,894 articles were initially retrieved. After the titles, abstracts, publication types, and full text of the publications were screened, we identified 49 articles that investigated the association between TILs and outcomes in EC patients. Among these articles, 19 were excluded after further indepth screening (12 for the lack of extractable important data, 5 for small sample size, and 2 for cohort duplication). Finally, 30 articles were included in our meta-analysis (Figure 1) (28). The total number of patients in our metaanalysis was 5,122 (range from 70 to 514 patients per study) and originated from Japan, China, Australia, Germany, France, Switzerland, Sweden and England.

Among the selected articles, only 8 reported the prognostic value of generalized TILs, while the remaining studies focused on specific TIL subsets (Table 1). Generalized TILs were detected with hematoxylin-eosin (HE) staining, while specific TIL subsets were identified with 


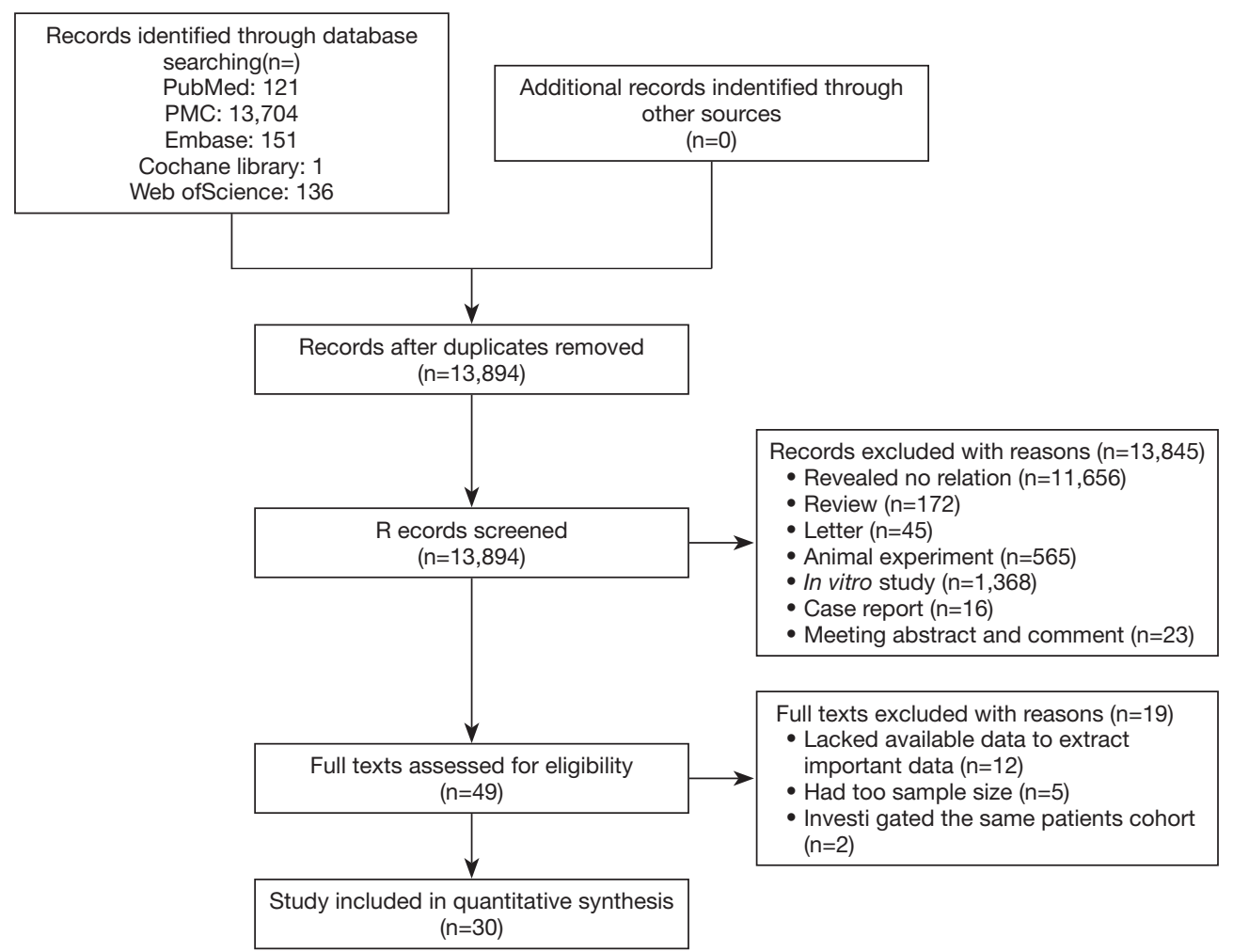

Figure 1 Flow diagram of the study selection process.

immunohistochemistry (IHC) staining and HE staining. The details of tumor stage were provided in 23 articles, although various categorization methods were applied. Follow-up time was mentioned in 19 articles. The cutoff values involved mean values $(n=6)$, median values $(n=11)$, and values from some semiquantitative methods. Of the 30 studies, only 10 provided Kaplan-Meier survival curves when reporting the survival as it related to a subset of TILs.

Quality assessment was performed for each study included in our meta-analysis according to the NOS, with scores ranging from 7 to 8 (mean, 7.87). A higher value indicates a better methodology. Therefore, all 30 studies were included in subsequent analyses.

\section{Generalized TILs}

Eight articles assessed the association between the density of generalized TILs and patient survival (29-36). Seven articles comprising 1,458 patients evaluated OS, and the pooled results showed that patients with a high level of generalized TILs had better OS (pooled HR $=0.67 ; 95 \%$ CI: 0.47-0.95; $\mathrm{P}=0.02$ ) (Figure 2, Table 2) than did patients with a lower level of generalized TILs. Of these 8 articles, 4 (involving 982 patients) evaluated DFS, and the pooled results showed that a high level of generalized TILs was not correlated with DFS (pooled HR $=1.13$; 95\% CI: 0.79-1.61; $\mathrm{P}=0.52$ ) (Figure 2, Table 2).

\section{CD8+ T-cell subset}

Twenty articles assessed the relationship between the density of the CD8+ T-cell subset and patient survival $(14,15,17,19-21,29,37-49) .17$ articles (12,14-17,19$21,29,39,40,43,44,46,47,49,50)$ comprising 2,529 patients evaluated OS, and the pooled results showed that patients with a high level of CD8+ TILs had better OS (pooled HR $=0.68 ; 95 \%$ CI: 0.60-0.78; $\mathrm{P}<0.001$ ) (Figure 3, Table 2) than did patients with a lower level of CD8+ TILs. Six articles $(16,17,20,21,29,46)$ comprising 1,180 patients evaluated DFS, and the pooled results showed that a high level of CD8+ TILs was not correlated with DFS (pooled $\mathrm{HR}=0.82 ; 95 \%$ CI: 0.67-1.01; $\mathrm{P}=0.06$ ) (Figure 3, Table 2). Finally, three articles $(38,41,45)$ comprising 400 patients evaluated CSS, and the pooled results showed that patients 


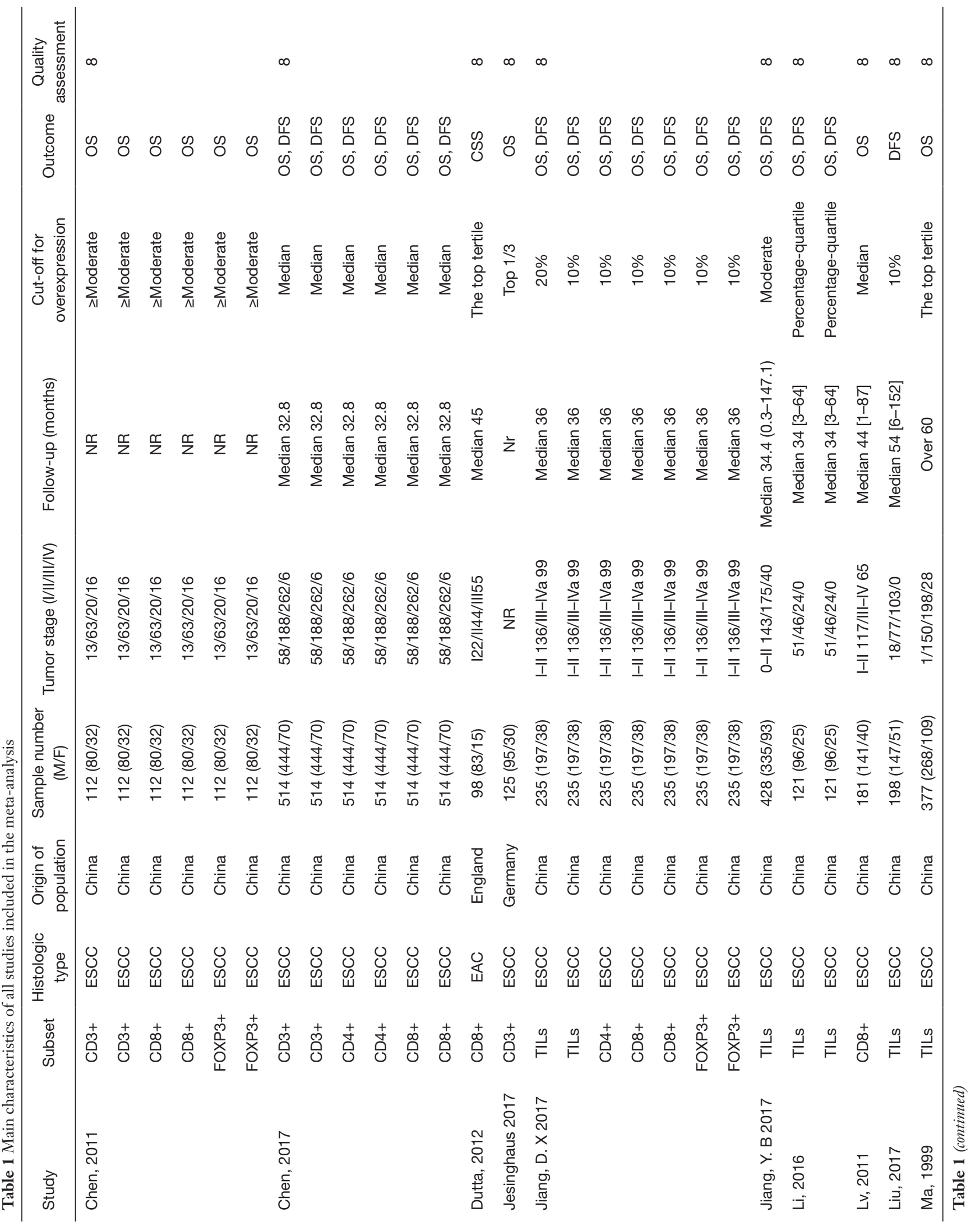




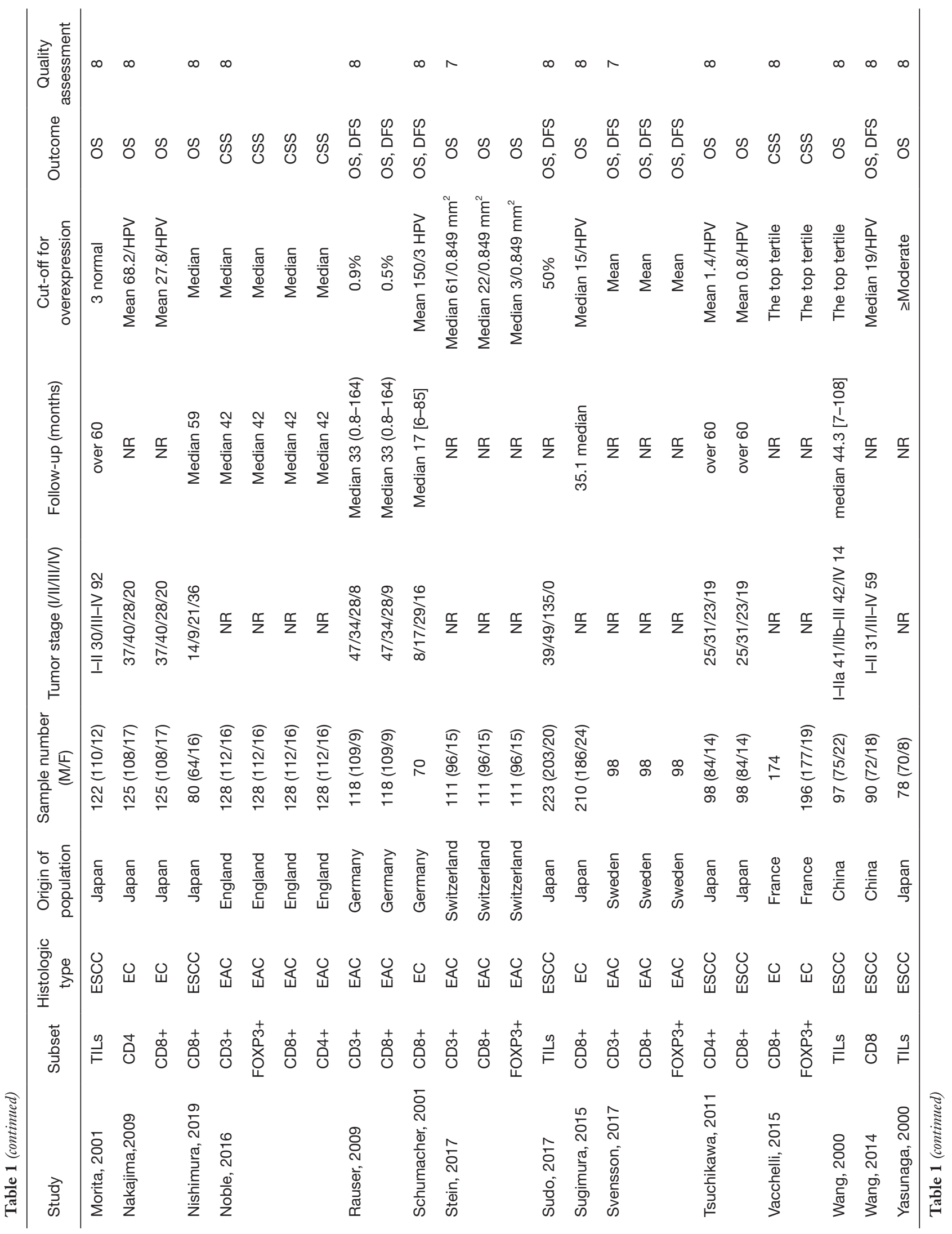




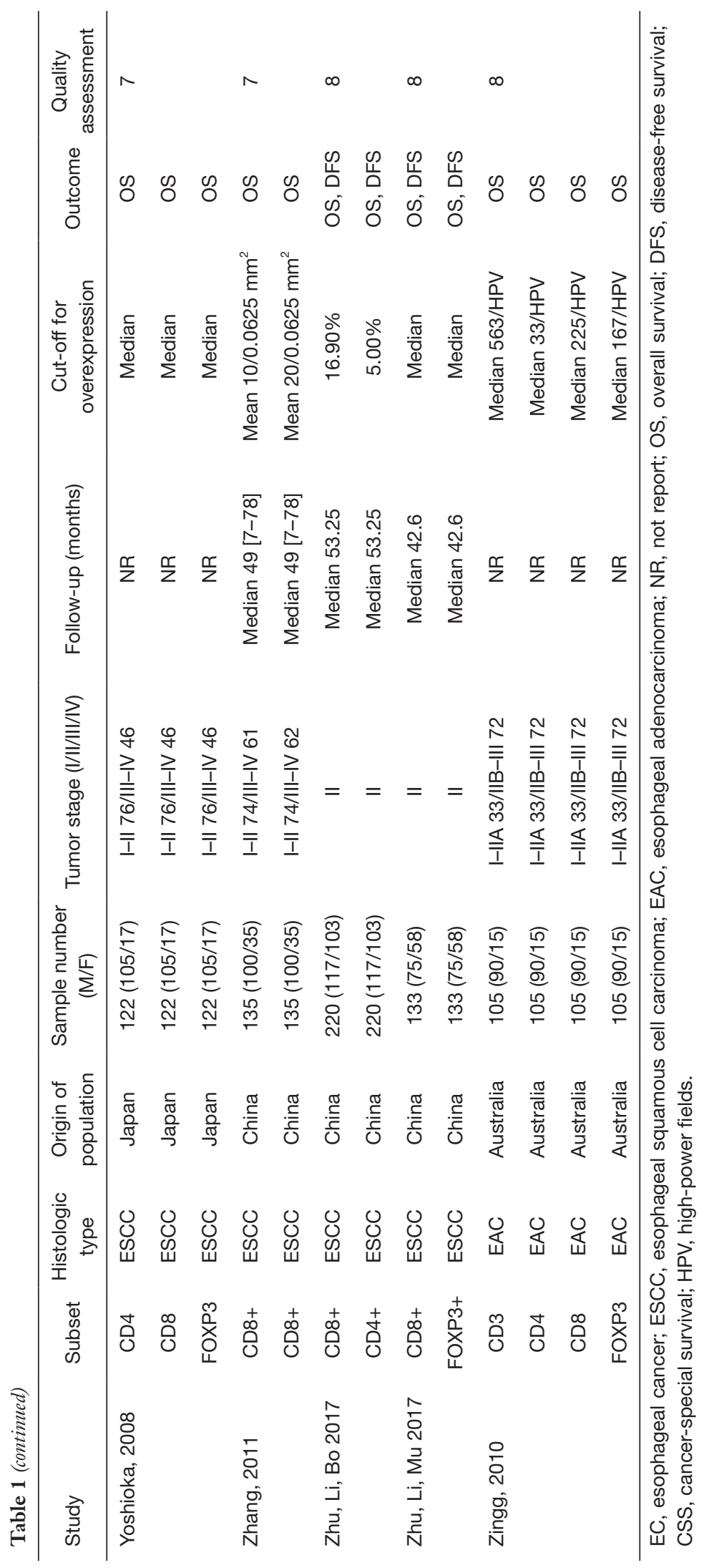




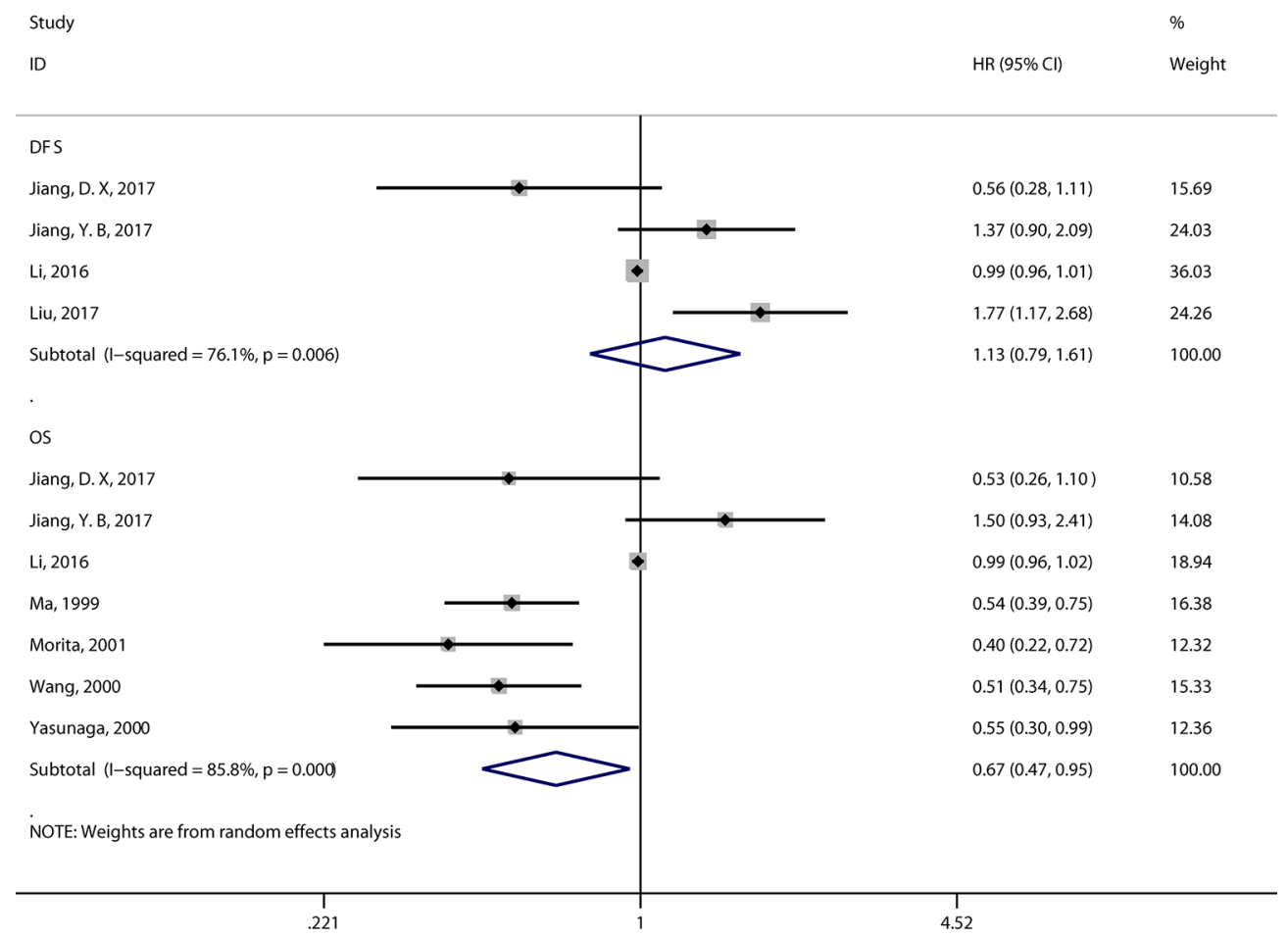

Figure 2 Forest plot for the prognostic effect of generalized TILs.

Table 2 The pooled associations between TILs subsets and the prognosis of patients with esophageal cancer

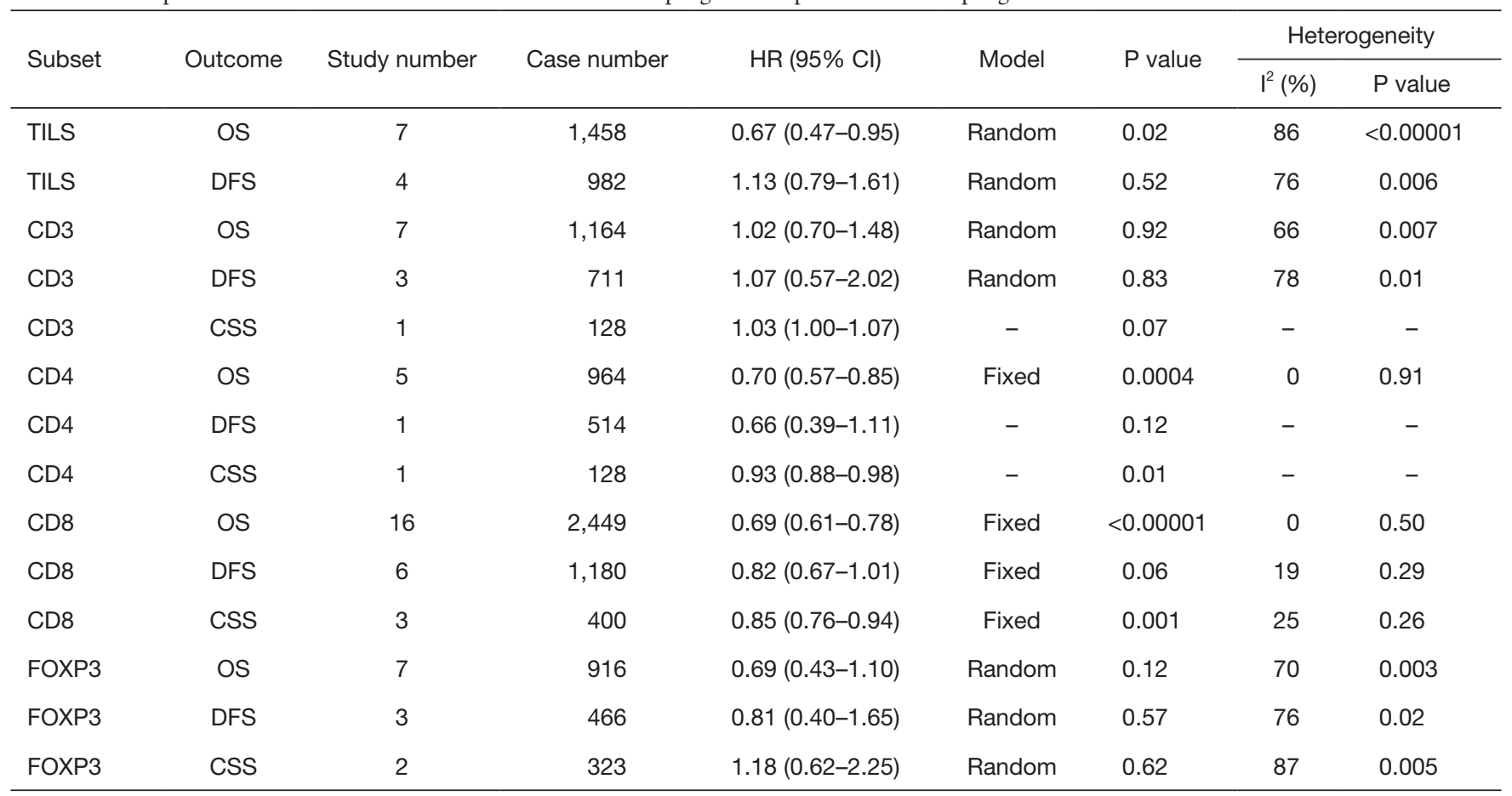

TILs, tumor-infiltrating lymphocytes; OS, overall survival; DFS, disease-free survival; CSS, cancer-special survival; HR, hazard ratio; CI, confidence intervals. 


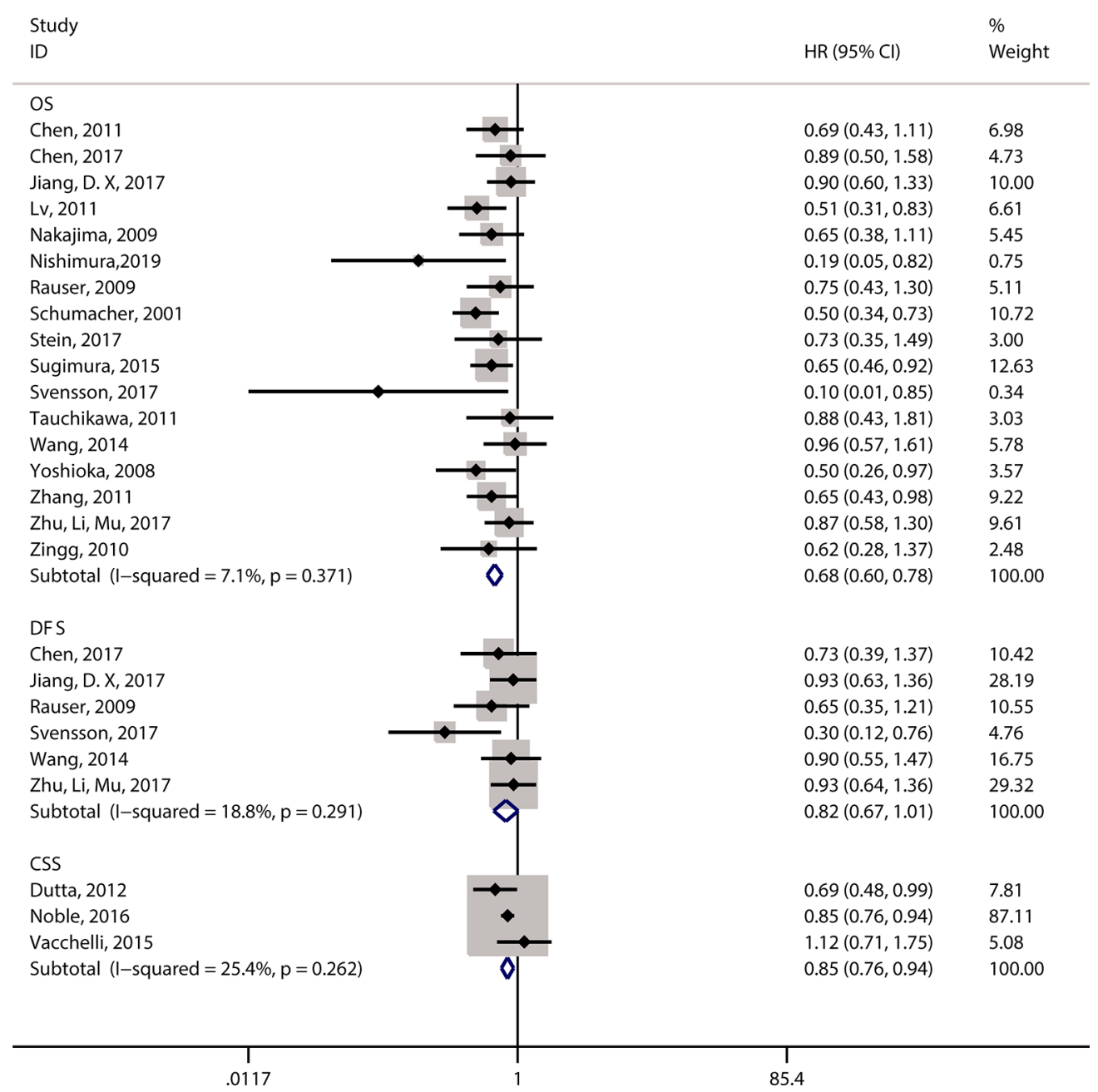

Figure 3 Forest plot for the prognostic effect of CD8+ T cells.

with a high level of CD8+ TILs had better CSS (pooled HR $=0.85 ; 95 \%$ CI: 0.76-0.94; $\mathrm{P}=0.001$ ) (Figure 3, Table 2) than did patients with a lower level of CD8+ TILs.

The subgroups were defined according to the patients' ethnicity, histology, sample size, cutoff values, publication year, and patients' country. The results showed that a high level of CD8+ TILs was associated with improved OS in patients with ESCC (pooled HR $=0.74,95 \%$ CI: 0.63-0.87; $\mathrm{P}=0.0005$ ), patients with EAC (pooled HR $=0.67,95 \%$ CI: 0.46-0.98; $\mathrm{P}=0.04)$, studies with a large sample size $(\geq 100$; pooled $\mathrm{HR}$ $=0.70,95 \%$ CI: $0.61-0.81 ; \mathrm{P}<0.001)$, and studies published after 2010 (pooled HR $=0.72$, 95\% CI: 0.63-0.84; $\mathrm{P}=0.02$ ) (Table 3). High levels of CD8+ TILs showed a better OS in both Asian patients (pooled HR $=0.72,95 \%$ CI: 0.62-0.83; $\mathrm{P}<0.001$ ) and Caucasian patients (pooled $\mathrm{HR}=0.58,95 \% \mathrm{CI}$ : 0.44-0.76; $\mathrm{P}<0.001$ ). In addition, high levels of CD8+ TILs indicated a better OS in patients from China (pooled HR $=0.76,95 \%$ CI: 0.64-0.91; P=0.002), Japan (pooled HR $=0.67$, 95\% CI: $0.53-0.84 ; \mathrm{P}<0.001$ ), and Germany (pooled HR $=0.57,95 \%$ CI: 0.42-0.78; $\mathrm{P}<0.001$ ) (Table 3).

Moreover, for ESCC, we also considered the distribution site of CD8+ TILs. Six studies that assessed the infiltration of CD8+ T lymphocytes in TNs also conducted an OS analysis $(14,16,17,19,29,50)$, the results of which suggested that patients with high CD8+ $\mathrm{T}$ lymphocyte infiltration in the TN had better OS (pooled HR $=0.70,95 \%$ CI: $0.57-0.85$; $\mathrm{P}=0.001$ ) (Figure 4). In addition, five studies that assessed the infiltration of CD8+ T lymphocytes in TS performed OS analysis $(14,16,19,29,39)$ and showed that high CD8+ $\mathrm{T}$ lymphocyte infiltration in TS significantly predicted better OS (pooled HR $=0.77,95 \%$ CI: $0.65-0.91 ; \mathrm{P}=0.003$ ) (Figure 4). Four studies researched CD8+ T lymphocyte 
Table 3 Subgroup analyses of the relationship between CD8+ T lymphocyte subsets and OS

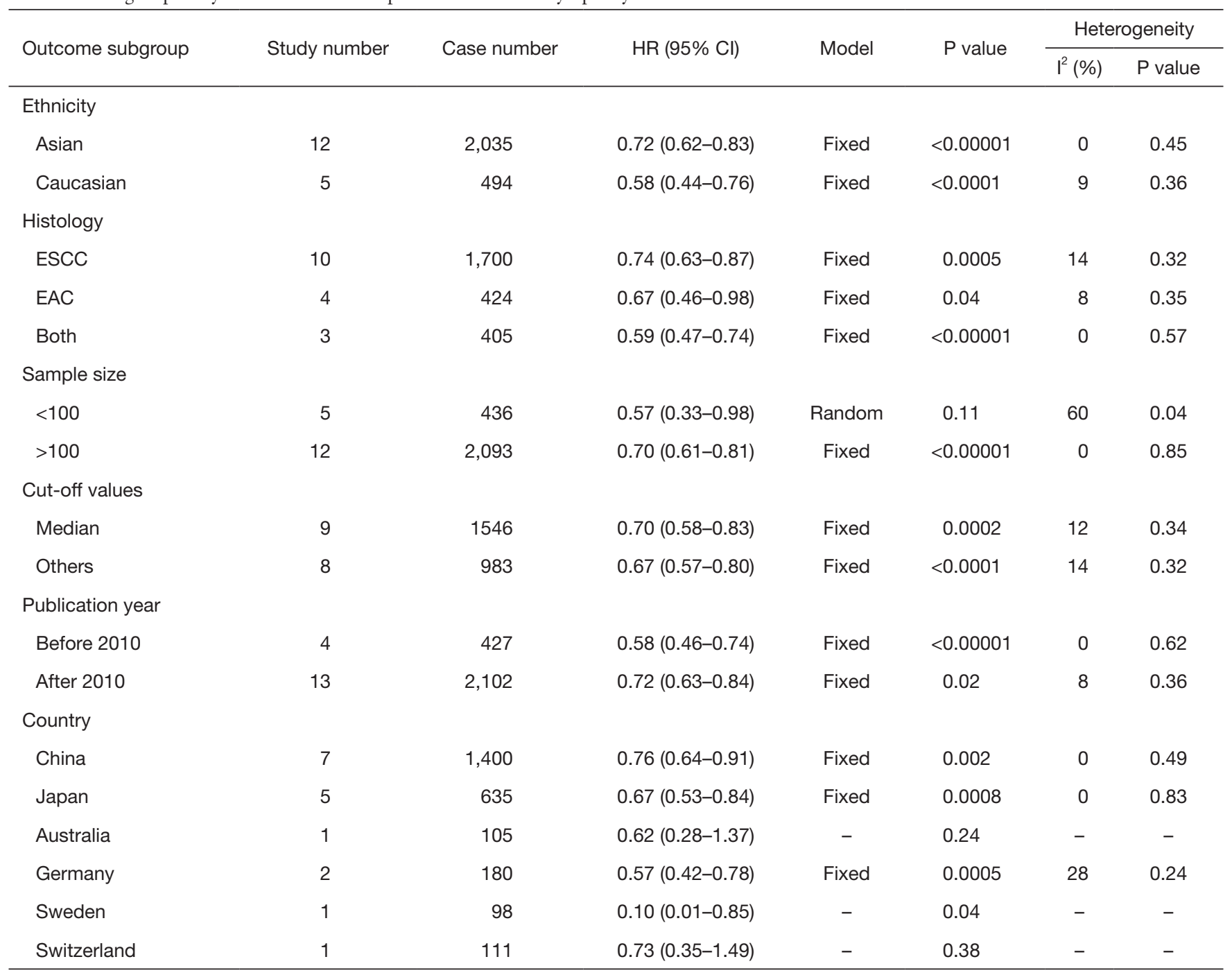

ESCC, esophageal squamous cell carcinoma; EAC, esophageal adenocarcinoma; OS, overall survival; HR, hazard ratio; CI, confidence intervals.

infiltration in both TNs and TS (44,46-48). However, the results showed that high levels of CD8+ T lymphocytes in both TNs and TS were not associated with OS (pooled HR $=0.82,95 \%$ CI: 0.63-1.07; P=0.14) (Figure 4).

\section{CD3+T-cell subset}

Eight studies investigated the prognostic value of CD3+ TILs in patients with EC. Seven studies (14-16,20,21,49,51) comprising 1,164 patients evaluated OS, and the pooled results showed that high level of CD3+ TILs were not associated with OS (pooled HR $=1.02$; 95\% CI: 0.70-1.48; $\mathrm{P}=0.92$ ) (Figure 5, Table 2). Three studies $(16,20,21)$ comprising 711 patients evaluated DFS, and the pooled results showed that high level of CD3+ TILs were also not associated with DFS (pooled HR $=1.07$; 95\% CI: 0.57-2.02; $\mathrm{P}=0.83$ ) (Figure 5, Table 2).

\section{CD4+ T-cell subset}

Six studies investigated the prognostic value of CD4+ TILs in patients with EC. Five studies $(16,44,47,49)$ comprising 964 patients evaluated OS, and the pooled results showed that high levels of CD4+ TILs were associated with better OS (pooled HR $=0.70 ; 95 \%$ CI: $0.57-0.85 ; \mathrm{P}<0.001$ ) (Figure 6, Table 2) compared to lower levels of C4+ TILs. 


\begin{tabular}{|c|c|c|}
\hline \multirow{2}{*}{$\begin{array}{l}\text { Study } \\
\text { ID }\end{array}$} & \multirow[b]{2}{*}{$\mathrm{HR}(95 \% \mathrm{Cl})$} & $\%$ \\
\hline & & Weight \\
\hline \multicolumn{3}{|l|}{ tumor nest } \\
\hline Chen, 2011 & $0.69(0.43,1.11)$ & 18.22 \\
\hline Chen, 2017 & $0.89(0.50,1.58)$ & 12.34 \\
\hline Jiang, D. X, 2017 & $0.90(0.60,1.33)$ & 26.12 \\
\hline Lv, 2011 & $0.51(0.31,0.83)$ & 17.27 \\
\hline Nishimura,2019 & $0.19(0.05,0.82)$ & 1.96 \\
\hline Zhang, 2011 & $0.65(0.43,0.98)$ & 24.08 \\
\hline Subtotal $(I-$ squared $=28.1 \%, p=0.224)$ & $0.70(0.57,0.85)$ & 100.00 \\
\hline \multicolumn{3}{|l|}{ tumor stroma } \\
\hline Chen, 2011 & $0.68(0.43,1.08)$ & 14.06 \\
\hline Chen, 2017 & $0.65(0.40,1.05)$ & 13.05 \\
\hline Jiang, D. X, 2017 & $0.90(0.63,1.29)$ & 22.59 \\
\hline Zhang, 2011 & $0.62(0.41,0.94)$ & 17.30 \\
\hline Zhu, Li, Bo, 2017 & $0.87(0.64,1.17)$ & 32.99 \\
\hline Subtotal $(I-$ squared $=0.0 \%, p=0.543)$ & $0.77(0.65,0.91)$ & 100.00 \\
\hline \multicolumn{3}{|l|}{ both tumor nest and stroma } \\
\hline Tauchikawa, 2011 & $0.88(0.43,1.81)$ & 13.78 \\
\hline Wang, 2014 & $0.96(0.57,1.61)$ & 26.30 \\
\hline Yoshioka, 2008 & $0.50(0.26,0.97)$ & 16.22 \\
\hline Zhu, Li, Mu, 2017 & $0.87(0.58,1.30)$ & 43.69 \\
\hline Subtotal $(\mid-$ squared $=0.0 \%, p=0.463)$ & $0.82(0.63,1.07)$ & 100.00 \\
\hline$T$ & & \\
\hline
\end{tabular}

Figure 4 Subgroup analysis of the prognostic effect of CD8+ T cells in esophageal squamous cell carcinoma.

\section{FOXP3+ T-cell subset}

Nine studies investigated the prognostic value of FOXP $3+$ TILs in patients with EC. Seven studies $(14,15,17,20,29,47,49)$ comprising 916 patients evaluated OS, and the pooled results showed that FOXP3+ TILs were not associated with OS (pooled HR $=0.69 ; 95 \%$ CI: $0.43-$ 1.10; $\mathrm{P}=0.12$ ) (Figure 7, Table 2). Three studies $(17,20,29)$ comprising 466 patients evaluated DFS, and the pooled results showed that FOXP3+ TILs were not associated with DFS (pooled HR $=0.81 ; 95 \% \mathrm{CI}: 0.40-1.65 ; \mathrm{P}=0.57$ ) (Figure 7, Table 2).

\section{Publication bias}

Because the subgroup analyzing the relationship between CD8+ TILs and OS contained 17 studies, it is necessary to evaluate the publication bias of this subgroup. The $\mathrm{P}$ values of the Egger's $(\mathrm{P}=0.112)$ and Begg's tests $(\mathrm{P}=0.303)$ were both greater than 0.05 (Figure $8 A, B$ ), indicating that no significant publication bias was observed.

\section{Discussion}

Many studies published in recent years have demonstrated that the various TIL subsets possess different prognostic predictive values in quite a few types of cancers, including gastric, breast, colorectal, and lung cancers (5-7,52-57). However, to the best of our knowledge, the prognostic roles of TILs in EC remain controversial. It has been repeatedly mentioned in previous studies that different subsets of lymphocytes may have different and even opposing prognostic effects, which makes sense in terms of the different functions of the corresponding subsets of lymphocytes in the tumor microenvironment. A metaanalysis published by Zheng et al. demonstrated that some TIL subsets could serve as prognostic biomarkers for EC patients (58). The two main differences between our metaanalysis and the previous one is as follows: (I) In our metaanalysis, 30 observational studies (comprising 5,122 patients) were summarized; however, the previous meta-analysis included only 22 studies and 2,909 patients. (II) In Zheng's meta-analysis, the researchers combined ESCC and EAC, 


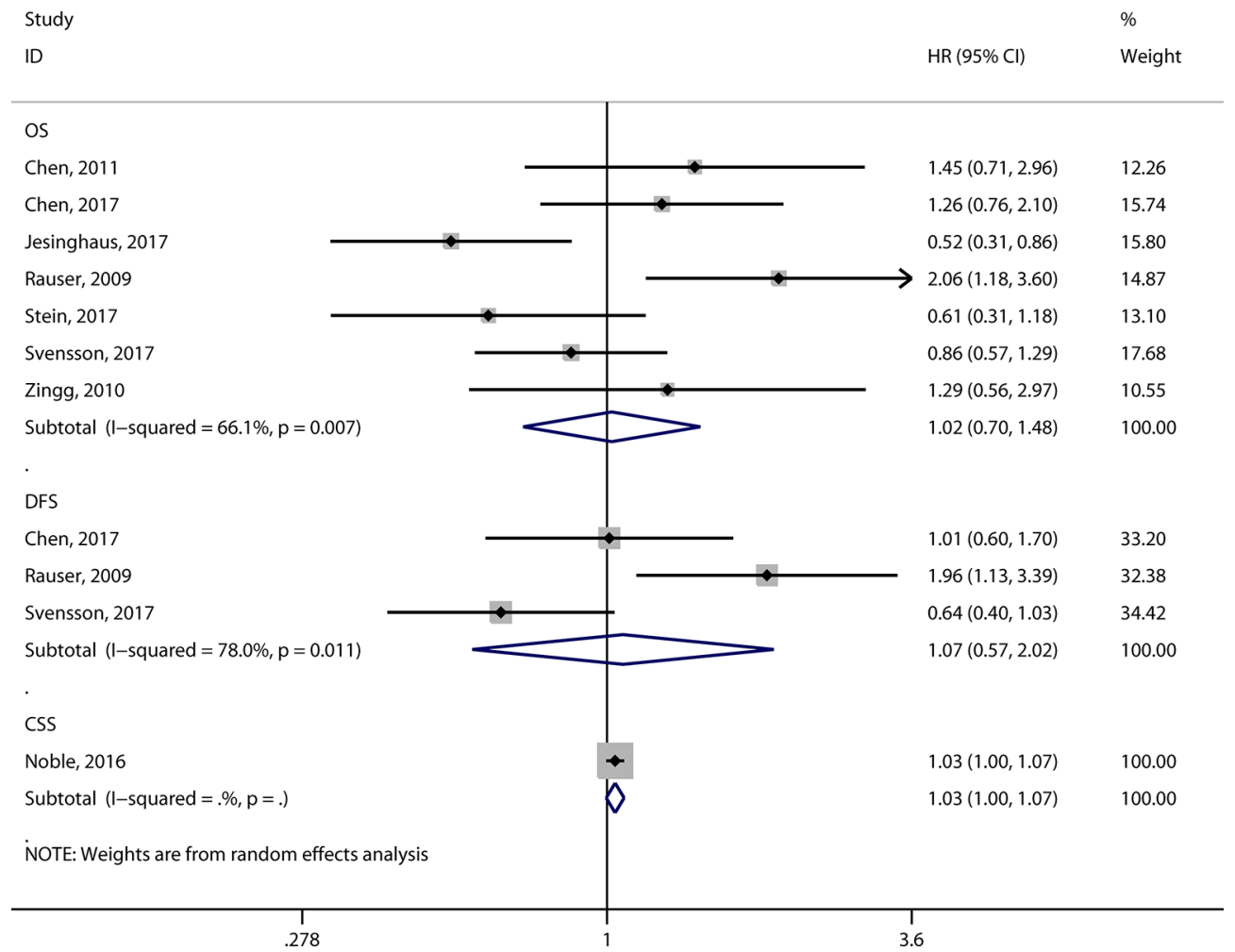

Figure 5 Forest plot for the prognostic effect of CD3+ T cells.

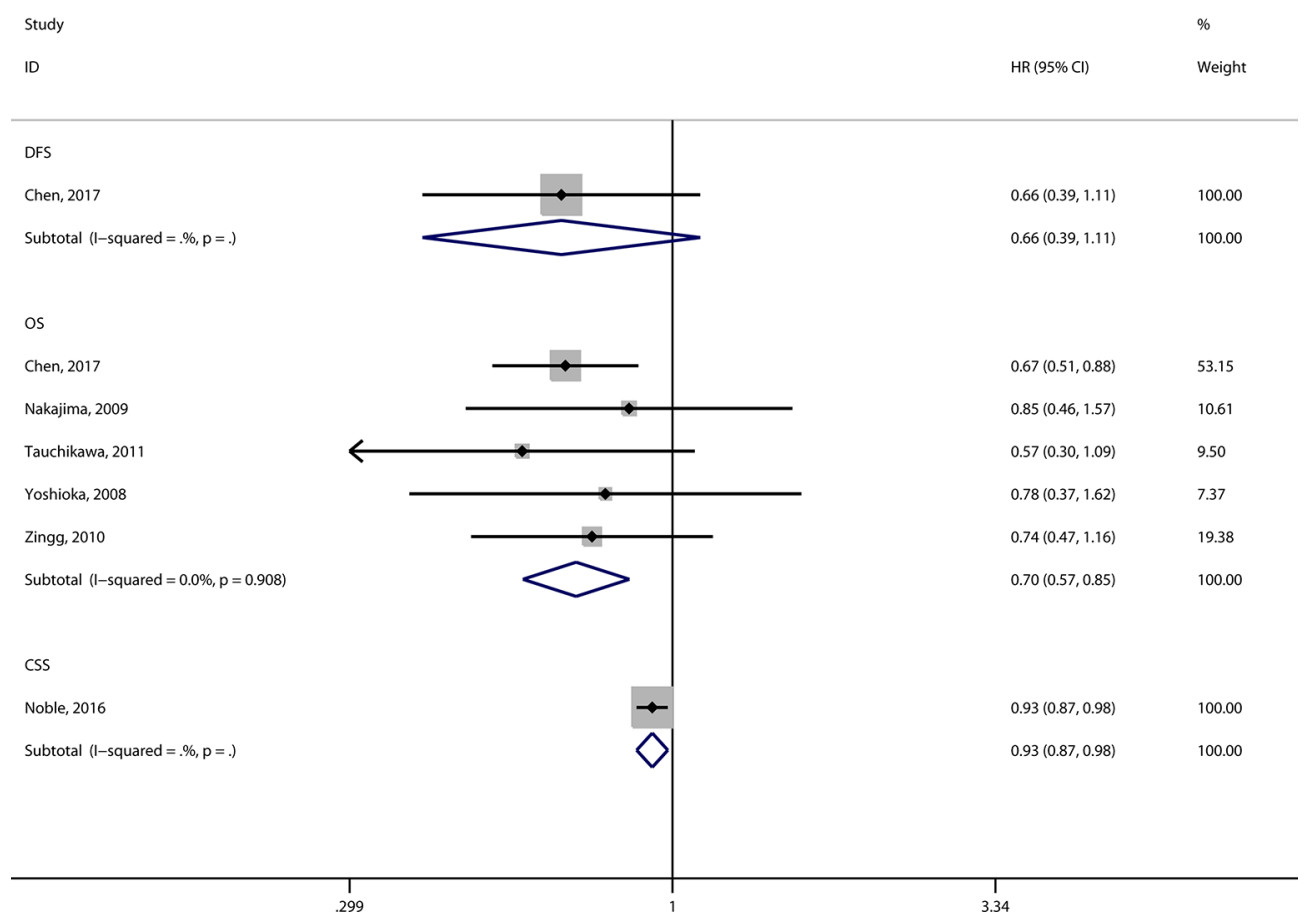

Figure 6 Forest plot for the prognostic effect of CD4+ T cells. 


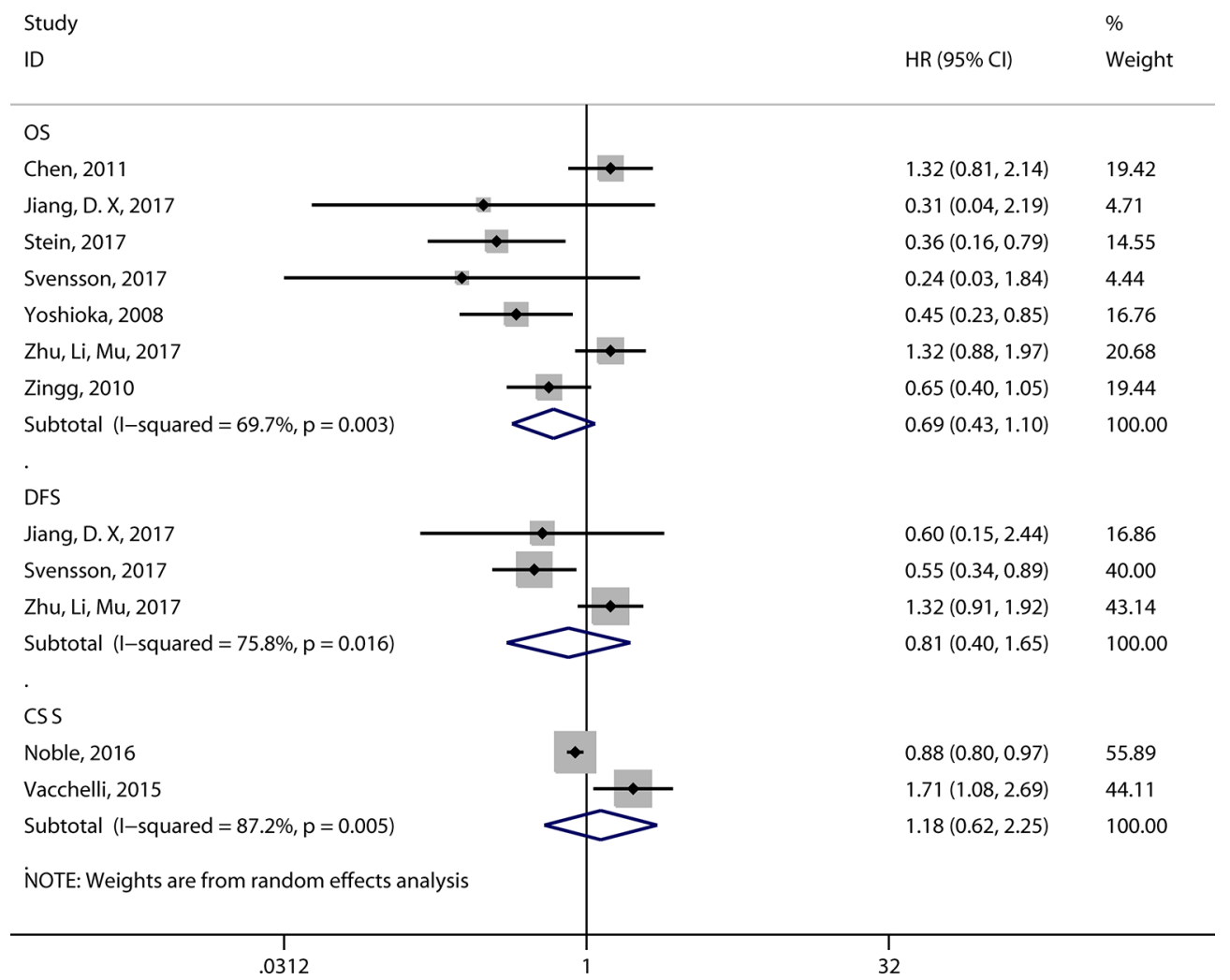

Figure 7 Forest plot for the prognostic effect of FOXP3 + T cells.
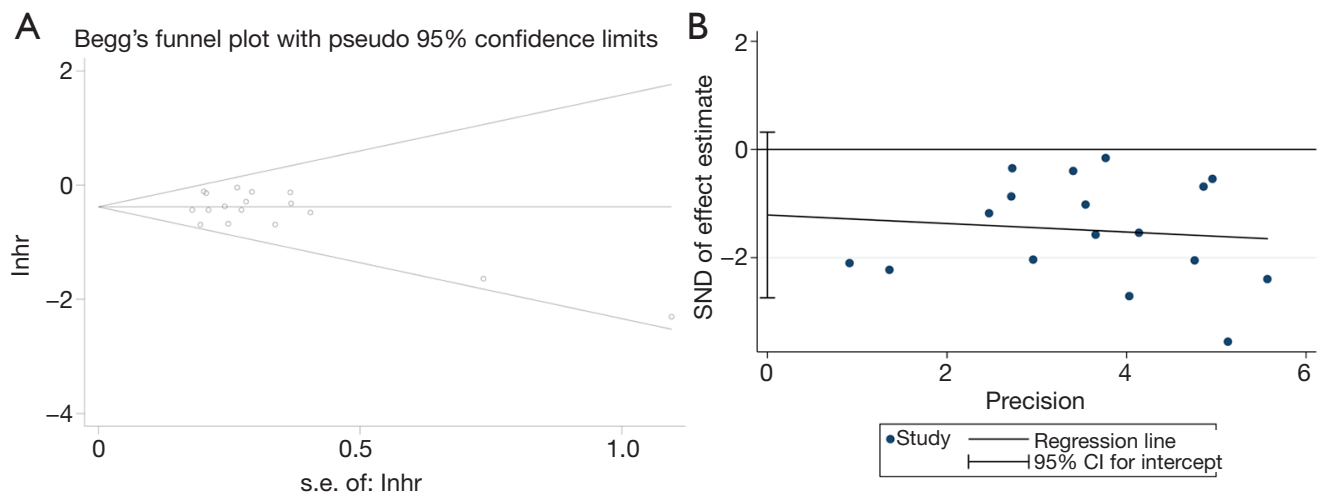

Figure 8 Begg's funnel plot and Egger's test for the assessment of potential publication bias in studies investigating the association between CD8+ TILs and overall survival of patients with esophageal cancer. No evidence of publication bias is observed. (A) Begg's $\mathrm{P}=0.303$. (B) Egger's $\mathrm{P}=0.112$.

and they did not mention the prognostic effect of TILs in different locations (in ESCC). Molecular analysis has shown that ESCC are more reminiscent of other SCCs than of EAC, which itself bears a striking resemblance to chromosomal instability (CIN) gastric cancer (59). In our meta-analysis, we performed subgroup analyses to investigate the prognostic value of CD8+ TILs for both ESCC and EAC patients. Moreover, we also investigated the prognostic effect of CD8+ TILs in both the TNs and TS in ESCC patients. Taking these results and insights into account, our meta-analysis was more comprehensive and stratified TILs according to their subsets and locations within the tumor 
microenvironment in both ESCC and EAC.

In our studies, generalized TILs indicate overall TILs regardless of the subtypes and location. Generalized TILs were reported in eight studies, and the evaluation of TILs was conducted on HE-stained tumor sections without further distinguishing subgroups by IHC. According to our results, a high density of generalized TILs was associated with favorable clinical outcomes. This result was in accordance with many previous studies in which the prognostic role of generalized TILs was evaluated $(5-7,52,60)$. In our study, a high level of CD $8+$ T-cell infiltration could predict a better OS for EC. The results are in agreement with the findings of previous studies that showed an association between $\mathrm{CD} 8+\mathrm{T}$ cells and better prognosis in other types of cancers $(5,7,52,55,60)$. In the subgroup analysis, high CD8+ T-cell infiltration was associated with favorable clinical outcomes in almost every subgroup analyzed, such as patients with ESCC, patients with EAC, Asian patients, Caucasian patients, and patients from China, Japan, or Germany. Moreover, in ESCC, a high number of CD8+ T cells in the TN or TS could predict a better OS for ESCC patients. These results indicate that $\mathrm{CD} 8+\mathrm{T}$-cell infiltration plays a definite anticancer role in EC. In our study, high CD4+ TIL infiltration was also a favorable prognostic biomarker. Although the prognostic value of CD4+ TIL infiltration was assessed by several studies, the role of CD4+ lymphocytes in the tumor microenvironment still remains questionable. CD4+ lymphocytes can exert different functions, ranging from the cytotoxic cell response of stimulated Th1 cells to the immunosuppressive response of regulatory $\mathrm{T}$ (Treg) cells $(61,62)$. FOXP3 is the most specific marker on Treg cells, which are commonly considered immunosuppressive. A study reported the negative prognostic role of FOXP3+ cells (63), while other studies found that a high level of FOXP3 + lymphocyte infiltration is a positive prognostic marker $(37,64)$. A meta-analysis by Shang et al. concluded that FOXP3 + Treg cells were associated with improved survival in several types of cancers, including EC. Furthermore, the molecular subtype and tumor stage significantly influenced the prognostic value of FOXP3+ TILs (65). According to our meta-analysis, high levels of FOXP3+ lymphocyte infiltration were not correlated with a favorable prognosis in EC patients. Finally, we assessed the prognostic value of CD3+ TILs. CD3 is a general surface antigen of $\mathrm{T}$ cells, which may represent the entire tumorinfiltrating $\mathrm{T}$ cell population (66). Due to the complex functions of different kinds of T cells, CD3+ TILs may not correlate with patients' clinical outcome, which is also consistent with our meta-analysis.

At present, the mainstream approach for predicting the clinical outcome in cancer patients is still the traditional TNM classification based on histopathological examination of surgically resected tumor tissues. However, it has been recognized for a long time that the TNM staging system is not precise enough, as survival outcomes can vary significantly among patients within the same stage (67). For many years, researchers have been exploring ways to complement TNM staging with immunologically relevant biomarkers; this can be referred to as "immunoscore". In the last few years, achievements have been made to include the prognostic value of immunological biomarkers to TNM staging in various types of cancers $(9,68-71)$. To date, many attempts have been made to explore the prognostic value of various TIL subsets for EC patients. To the best of our knowledge, this is the most comprehensive meta-analysis to systematically combine data regarding the prognostic roles of various subsets of TILs in EC. Moreover, the results of our study should be interpreted with caution for the following reasons. First, the main limitation of this study is the heterogeneity within the tumor subgroups, cutoff values and detecting methods included in our metaanalysis. Molecular analysis has shown that ESCC are more reminiscent of other SCCs than of EAC. So, the prognostic value of TILs may be different between these two different tumor subgroups. Moreover, because now there is no consensus on cut-offs, several studies were unclear about their data-dependent cut-offs, and this may lead to different results. In addition, Because the detection methods of TILs may also be different, and this also affect the results. we need to conduct multi-center, prospective researches which use homogeneous cohorts to determine the appropriate T-cell makers, cut-off values and detection methods. Second, as HRs were not provided directly by some of the included studies, the required data had to be extracted from survival curves, which would undoubtedly introduce measurement error. Third, some studies only applied univariate Cox regression analysis, which tended to overestimate the prognostic effects of TILs, as other influencing factors were not adequately controlled. Fourth, in our meta-analysis, some studies included patients who received neoadjuvant treatment, but the separate HRs of these patients were not provided. Other studies only included patients who did not receive neoadjuvant treatment, which undoubtedly caused a bias. Finally, for some TIL subsets, data could only be obtained from a single study; thus, data integration was 
not feasible. Overall, for most TIL subsets, corresponding studies that assessed their prognostic values did not have a sufficient number of patients within their cohorts. However, this problem is inevitable to some extent, as studies focusing on the prognostic roles of TILs in EC patients are far from abundant.

In summary, we found that high levels of generalized TILs, high CD8+ T-cell infiltration and high CD4+ T-cell infiltration were associated with better OS in EC patients. Moreover, high numbers of CD8+ TILs in the TN or TS can predict better OS for ESCC patients. Additional randomized controlled trials with larger sample sizes are needed to determine the most promising combination of TILs for the establishment of an immunoscore for patients with EC.

\section{Acknowledgments}

We thank Ms. Meihua Xiong, Fang Zhou and all the staff in Dr. Jie He's Laboratory, Department of Thoracic Surgery, for their support during the study.

Funding: This study was supported by the National Key R\&D Program of China (2018YFC1313100, 2016YFC1303200), the National Natural Science Foundation of China (81972316), the Beijing Nova Program (Z181100006218032), the CAMS Innovation Fund for Medical Sciences (CIFMS) (2017-I2M-1-005, 2017 I2M-2-003), and the Institutional Fundamental Research Funds (2018PT32012, PY2018B02, 2019PT320022).

\section{Footnote}

Reporting Checklist: The authors have completed the PRISMA 2009 reporting checklist. Available at http:// dx.doi.org/10.21037/atm-20-151

Conflicts of Interest: All authors have completed the ICMJE uniform disclosure form (available at http://dx.doi. org/10.21037/atm-20-151). The authors have no conflicts of interest to declare.

Etbics Statement: The authors are accountable for all aspects of the work in ensuring that questions related to the accuracy or integrity of any part of the work are appropriately investigated and resolved. All analyses in this meta-analysis were based on previous published studies which have been performed in accordance with the Declaration of Helsinki (as revised in 2013) and approved by an appropriate ethics committee.
Open Access Statement: This is an Open Access article distributed in accordance with the Creative Commons Attribution-NonCommercial-NoDerivs 4.0 International License (CC BY-NC-ND 4.0), which permits the noncommercial replication and distribution of the article with the strict proviso that no changes or edits are made and the original work is properly cited (including links to both the formal publication through the relevant DOI and the license). See: https://creativecommons.org/licenses/by-nc-nd/4.0/.

\section{References}

1. Pennathur A, Gibson MK, Jobe BA, et al. Oesophageal carcinoma. Lancet 2013;381:400-12.

2. Rustgi AK, El-Serag HB. Esophageal carcinoma. N Engl J Med 2014;371:2499-509.

3. Montgomery E, Basman F, Brennan P, et al. Oesophageal cancer. World Cancer Report 2014:374-82.

4. Jain S, Dhingra S. Pathology of esophageal cancer and Barrett's esophagus. Ann Cardiothorac Surg 2017;6:99-109.

5. Geng Y, Shao Y, He W, et al. Prognostic role of tumorinfiltrating lymphocytes in lung cancer: a meta-analysis. Cell Physiol Biochem 2015;37:1560-71.

6. Ibrahim EM, Al-Foheidi ME, Al-Mansour MM, et al. The prognostic value of tumor-infiltrating lymphocytes in triple-negative breast cancer: a meta-analysis. Breast Cancer Res Treat 2014;148:467-76.

7. Mei Z, Liu Y, Liu C, et al. Tumour-infiltrating inflammation and prognosis in colorectal cancer: systematic review and meta-analysis. Br J Cancer 2014;110:1595.

8. Lee N, Zakka LR, Mihm MC Jr, et al. Tumour-infiltrating lymphocytes in melanoma prognosis and cancer immunotherapy. Pathology 2016;48:177-87.

9. Yao Q, Bao X, Xue R, et al. Prognostic value of immunoscore to identify mortality outcomes in adults with $\mathrm{HBV}$-related primary hepatocellular carcinoma. Medicine (Baltimore) 2017;96:e6735.

10. Li J, Wang J, Chen R, et al. The prognostic value of tumor-infiltrating $\mathrm{T}$ lymphocytes in ovarian cancer. Oncotarget 2017;8:15621.

11. Balch CM, Riley LB, Bae YJ, et al. Patterns of human tumor-infiltrating lymphocytes in 120 human cancers. Arch Surg 1990;125:200-5.

12. Schreiber RD, Old LJ, Smyth MJ. Cancer immunoediting: integrating immunity's roles in cancer suppression and promotion. Science 2011;331:1565-70.

13. Whiteside TL. The tumor microenvironment and its role 
in promoting tumor growth. Oncogene 2008;27:5904.

14. Chen LJ, Sun J, Wu HY, et al. B7-H4 expression associates with cancer progression and predicts patient's survival in human esophageal squamous cell carcinoma. Cancer Immunol Immunother 2011;60:1047-55.

15. Stein AV, Dislich B, Blank A, et al. High intratumoural but not peritumoural inflammatory host response is associated with better prognosis in primary resected oesophageal adenocarcinomas. Pathology 2017;49:30-7.

16. Chen K, Zhu Z, Zhang N, et al. Tumor-Infiltrating CD4+ Lymphocytes Predict a Favorable Survival in Patients with Operable Esophageal Squamous Cell Carcinoma. Med Sci Monit 2017;23:4619-32.

17. Zhu Y, Li M, Bo C, et al. Prognostic significance of the lymphocyte-to-monocyte ratio and the tumor-infiltrating lymphocyte to tumor-associated macrophage ratio in patients with stage T3N0M0 esophageal squamous cell carcinoma. Cancer Immunol Immunother 2017;66:343-54.

18. Zhang Y, Li Y, Guo W, et al. The expression of tumorinfiltrating lymphocytes and its relationship with prognosis of esophageal carcinoma. Tumor 2009;29:363-6.

19. Zhang G, Liu WL, Zhang L, et al. Involvement of Indoleamine 2, 3-Dioxygenase in Impairing TumorInfiltrating CD8. Clin Dev Immunol 2011;2011:384726.

20. Svensson MC, Warfvinge CF, Fristedt R, et al. The integrative clinical impact of tumor-infiltrating $\mathrm{T}$ lymphocytes and NK cells in relation to B lymphocyte and plasma cell density in esophageal and gastric adenocarcinoma. Oncotarget 2017;8:72108.

21. Rauser S, Langer R, Tschernitz S, et al. High number of CD45RO+ tumor infiltrating lymphocytes is an independent prognostic factor in non-metastasized (stage I-IIA) esophageal adenocarcinoma. BMC Cancer 2010;10:608.

22. Liberati A, Altman DG, Tetzlaff J, et al. The PRISMA statement for reporting systematic reviews and metaanalyses of studies that evaluate health care interventions: explanation and elaboration. PLoS Med 2009;6:e1000100.

23. Stroup DF, Berlin JA, Morton SC, et al. Meta-analysis of observational studies in epidemiology: a proposal for reporting. JAMA 2000;283:2008-12.

24. Stang A. Critical evaluation of the Newcastle-Ottawa scale for the assessment of the quality of nonrandomized studies in meta-analyses. Eur J Epidemiol 2010;25:603-5.

25. Tierney JF, Stewart LA, Ghersi D, et al. Practical methods for incorporating summary time-to-event data into metaanalysis. Trials 2007;8:16.

26. Higgins JP, Thompson SG. Quantifying heterogeneity in a meta-analysis. Stat Med 2002;21:1539-58.

27. Higgins JP, Thompson SG, Deeks JJ, et al. Measuring inconsistency in meta-analyses. BMJ 2003;327:557.

28. Wang Y, Chen J, Meng L, et al., A histopathologic and immunohistochemical study of prognostic factors in esophageal squamous cell carcinoma. Zhonghua Bing Li Xue Za Zhi 2000;29:267-71.

29. Jiang D, Liu Y, Wang H, et al. Tumour infiltrating lymphocytes correlate with improved survival in patients with esophageal squamous cell carcinoma. Sci Rep 2017;7:44823.

30. Jiang Y, Lo AW, Wong A, et al. Prognostic significance of tumor-infiltrating immune cells and PD-L1 expression in esophageal squamous cell carcinoma. Oncotarget 2017;8:30175.

31. Li J, Tang Y, Huang L, et al. A high number of stromal tumor-infiltrating lymphocytes is a favorable independent prognostic factor in M0 (stages I-III) esophageal squamous cell carcinoma. Dis Esophagus 2017;30:1-7.

32. Liu S, Anfossi S, Qiu B, et al. Prognostic factors for locoregional recurrence in patients with thoracic esophageal squamous cell carcinoma treated with radical two-field lymph node dissection: results from long-term follow-up. Ann Surg Oncol 2017;24:966-73.

33. Ma Y, Xian M, Li J, et al. Interrelations of clinicopathological variables, local immune response and prognosis in esophageal squamous cell carcinoma. APMIS 1999;107:514-22.

34. Morita M, Kuwano H, Araki K, et al. Prognostic significance of lymphocyte infiltration following preoperative chemoradiotherapy and hyperthermia for esophageal cancer. Int J Radiat Oncol Biol Phys 2001;49:1259-66.

35. Sudo T, Nishida R, Kawahara A, et al. Clinical impact of tumor-infiltrating lymphocytes in esophageal squamous cell carcinoma. Ann Surg Oncol 2017;24:3763-70.

36. Yasunaga M, Tabira Y, Nakano K, et al. Accelerated growth signals and low tumor-infiltrating lymphocyte levels predict poor outcome in T4 esophageal squamous cell carcinoma. Ann Thorac Surg 2000;70:1634-40.

37. Diana A, Wang LM, D'Costa Z, et al. Prognostic value, localization and correlation of PD-1/PD-L1, CD8 and FOXP3 with the desmoplastic stroma in pancreatic ductal adenocarcinoma. Oncotarget 2016;7:40992.

38. Dutta S, Going J, Crumley A, et al. The relationship between tumour necrosis, tumour proliferation, local and systemic inflammation, microvessel density and survival in patients undergoing potentially curative resection of 
oesophageal adenocarcinoma. Br J Cancer 2012;106:702.

39. Lv L, Pan K, Li XD, et al. The accumulation and prognosis value of tumor infiltrating IL-17 producing cells in esophageal squamous cell carcinoma. PLoS One 2011;6:e18219.

40. Nakajima M, Kato H, Miyazaki T, et al. Tumor immune systems in esophageal cancer with special reference to heat-shock protein 70 and humoral immunity. Anticancer Res 2009;29:1595-606.

41. Noble F, Mellows T, Matthews LHM, et al. Tumour infiltrating lymphocytes correlate with improved survival in patients with oesophageal adenocarcinoma. Cancer Immunol Immunother 2016;65:651-62.

42. Schumacher K, Haensch W, Röefzaad C, et al. Prognostic significance of activated CD8+ T cell infiltrations within esophageal carcinomas. Cancer Res 2001;61:3932-6.

43. Sugimura K, Miyata H, Tanaka K, et al. High infiltration of tumor-associated macrophages is associated with a poor response to chemotherapy and poor prognosis of patients undergoing neoadjuvant chemotherapy for esophageal cancer. J Surg Oncol 2015;111:752-9.

44. Tsuchikawa T, Ikeda H, Cho Y, et al. Association of CD8+ $T$ cell infiltration in oesophageal carcinoma lesions with human leucocyte antigen (HLA) class I antigen expression and survival. Clin Exp Immunol 2011;164:50-6.

45. Vacchelli E, Semeraro M, Enot DP, et al. Negative prognostic impact of regulatory $\mathrm{T}$ cell infiltration in surgically resected esophageal cancer postradiochemotherapy. Oncotarget 2015;6:20840.

46. Wang J, Jia Y, Wang N, et al. The clinical significance of tumor-infiltrating neutrophils and neutrophil-to-CD8+ lymphocyte ratio in patients with resectable esophageal squamous cell carcinoma. J Transl Med 2014;12:7.

47. Yoshioka T, Miyamoto M, Cho Y, et al. Infiltrating regulatory $\mathrm{T}$ cell numbers is not a factor to predict patient's survival in oesophageal squamous cell carcinoma. Br J Cancer 2008;98:1258.

48. Zhu Y, Li M, Mu D, et al. CD8+/FOXP3+ ratio and PDL1 expression associated with survival in pT3N0M0 stage esophageal squamous cell cancer. Oncotarget 2016;7:71455.

49. Zingg U, Montani M, Frey DM, et al. Tumour-infiltrating lymphocytes and survival in patients with adenocarcinoma of the oesophagus. Eur J Surg Oncol 2010;36:670-7.

50. Nishimura J, Tanaka H, Yamakoshi Y, et al. Impact of tumor-infiltrating LAMP-3 dendritic cells on the prognosis of esophageal squamous cell carcinoma. Esophagus 2019;16:333-44.
51. Jesinghaus M, Steiger K, Slotta-Huspenina J, et al. Increased intraepithelial CD3 + T-lymphocytes and high PD-L1 expression on tumor cells are associated with a favorable prognosis in esophageal squamous cell carcinoma and allow prognostic immunogenic subgrouping. Oncotarget 2017;8:46756.

52. Zheng X, Song X, Shao Y, et al. Prognostic role of tumorinfiltrating lymphocytes in gastric cancer: a meta-analysis. Oncotarget 2017;8:57386.

53. Gooden MJ, de Bock GH, Leffers N, et al. The prognostic influence of tumour-infiltrating lymphocytes in cancer: a systematic review with meta-analysis. Br J Cancer 2011;105:93.

54. Huang Y, Liao H, Zhang Y, et al. Prognostic value of tumor-infiltrating FoxP3 + T cells in gastrointestinal cancers: a meta analysis. PLoS One 2014;9:e94376.

55. Hwang W-T, Adams SF, Tahirovic E, et al. Prognostic significance of tumor-infiltrating T cells in ovarian cancer: a meta-analysis. Gynecol Oncol 2012;124:192-8.

56. Jiang D, Gao Z, Cai Z, et al. Clinicopathological and prognostic significance of FOXP3 + tumor infiltrating lymphocytes in patients with breast cancer: a metaanalysis. BMC Cancer 2015;15:727.

57. Qian F, Qingping Y, Linquan W, et al. High tumorinfiltrating FoxP3 + T cells predict poor survival in estrogen receptor-positive breast cancer: A meta-analysis. Eur J Surg Oncol 2017;43:1258-64.

58. Zheng X, Song X, Shao Y, et al. Prognostic Role of Tumor-Infiltrating Lymphocytes in Esophagus Cancer: a Meta-Analysis. Cell Physiol Biochem 2018;45:720-32.

59. Cancer Genome Atlas Research Network; Analysis Working Group: Asan University; BC Cancer Agency; Integrated genomic characterization of oesophageal carcinoma. Nature 2017;541:169-75.

60. Mao Y, Qu Q, Chen X, et al. The prognostic value of tumor-infiltrating lymphocytes in breast cancer: a systematic review and meta-analysis. PLoS One 2016;11:e0152500.

61. Kim HJ, Cantor H. CD4 T-cell subsets and tumor immunity: the helpful and the not-so-helpful. Cancer Immunol Res 2014;2:91-8.

62. Kennedy R, Celis E. Multiple roles for CD4+ T cells in anti-tumor immune responses. Immunol Rev 2008;222:129-44.

63. Xia M, Zhao MQ, Wu K, et al. Investigations on the clinical significance of FOXP3 protein expression in cervical oesophageal cancer and the number of FOXP3+ tumour-infiltrating lymphocytes. J Int Med Res 
2013;41:1002-8.

64. West NR, Kost S, Martin S, et al. Tumour-infiltrating FOXP3+ lymphocytes are associated with cytotoxic immune responses and good clinical outcome in oestrogen receptor-negative breast cancer. Br J Cancer 2013;108:155.

65. Shang B, Liu Y, Jiang SJ, et al. Prognostic value of tumorinfiltrating FoxP3 + regulatory T cells in cancers: a systematic review and meta-analysis. Sci Rep 2015;5:15179.

66. Wagner P, Koch M, Nummer D, et al. Detection and functional analysis of tumor infiltrating T-lymphocytes (TIL) in liver metastases from colorectal cancer. Ann Surg Oncol 2008;15:2310.

67. Galon J, Pagès F, Marincola FM, et al. Cancer classification using the Immunoscore: a worldwide task force. J Transl Med 2012;10:205.

Cite this article as: Gao Y, Guo W, Geng X, Zhang Y, Zhang G, Qiu B, Tan F, Xue Q, Gao S, He J. Prognostic value of tumorinfiltrating lymphocytes in esophageal cancer: an updated metaanalysis of 30 studies with 5,122 patients. Ann Transl Med 2020;8(13):822. doi: 10.21037/atm-20-151
68. Kim K-J, Yang HK, Kim WH, et al. Combined prognostic effect of PD-L1 expression and immunoscore in microsatellite-unstable advanced gastric cancers. Oncotarget 2017;8:58887.

69. Kwak Y, Koh J, Kim DW, et al. Immunoscore encompassing CD3 + and CD8+ T cell densities in distant metastasis is a robust prognostic marker for advanced colorectal cancer. Oncotarget 2016;7:81778.

70. Mlecnik B, Van den Eynde M, Bindea G, et al. Comprehensive intrametastatic immune quantification and major impact of immunoscore on survival. J Natl Cancer Inst 2018;110:djx123.

71. Wang M. ImmunoScore predicts gastric cancer postsurgical outcome. Lancet Oncol 2017;18:e68. 